\title{
CORROSION RESISTANCE OF TITANIUM BASED COMPOSITES REINFORCED WITH IN SITU TIB PRECIPITATION PHASE
}

\begin{abstract}
The paper presents the results of corrosion resistance tests carried out on titanium based composites reinforced with different TiB precipitation phase amount, dependent from boron addition in starting powder blends. Precursor powder preparation and processing parameters of conventional powder metallurgical approach influence density and obtained porosity of bulk compacts. The potentiodynamic tests performed in $0.1 \mathrm{M} \mathrm{NaCl}$ solution by the technique of linear voltammetry shows visible difference between compared composite structures. Studies have confirmed that the reinforcement phase amount and its morphology influence obtained microstructure and have important effect on the composite corrosion resistance.

Keywords: Corrosion resistance, titanium based composites, composite microstructure, in situ TiB reinforcement phase
\end{abstract}

\section{Introduction}

Titanium and its alloys possess properties desirable for a different range of application alike high specific strength or corrosion resistance, however, in the same they characterize for example with limited hardness and wear resistance [1]. Growing interest and realized research based on the new concept of the product manufacturing tries to overcome mentioned limitations [2-4]. Manufacturing strategies which tend to decrease the cost of the production understand as a restriction of intermediate operations, focusing more often whenever on Metal Matrix Composites (MMC) materials [5]. Proposed in realized research titanium-based composite with in-situ TiB reinforcement phase recognize as highly perspective material maintain as not fully characterized proposal, mainly when different processing approach is considered [6-8]. For example, the mechanical alloying process used as a first step procedure of powder blends preparation may lead to final properties change $[9,10]$. Lower starting grain size increases the potential for the reaction kinetics in the system and in the same may diminish the amount of substrate additions or reaction temperatures in considered examples [10]. The reaction kinetics between the substrates influences the final phase composition (in most cases dependent on the presence of some residual phase) and by its different volumetric ratio change resultant properties of analysed examples. In most cases reported improvement for Ti-TiB MMC that results from a good interface between the matrix and reinforcement, its favourable orientation relationship as also close thermal coefficient factor, may lead in the fully optimized process to the perspective commercial application [11]. This work tries to summarize the efforts made on a three different precursor composition used for composite structure preparation and its corrosion resistance properties examination.

\section{Materials and methods}

Investigation on the in situ reinforced composite structure was started from precursor materials preparation. Three boron weight amounts to titanium composition with: 2,5 and $10 \%$, were prepared in micro $(\mathrm{M})$ and nano $(\mathrm{N})$ form from the metallic elements of the $\mathrm{Ti}$ and $\mathrm{B}$ with $99,8 \%$ purity level. Powders blends of (Ti, B: $<45 \mu \mathrm{m}$ ) were mixed in the glove box (LabMaster 130) with the high purity argon atmosphere and poured into the hardened tool steel vial. Micro character precursor compositions were prepared by ball-milling (BM) in the Spex Mixer Mill that was run for 5 minutes. Nano precursor compositions were obtained by $48 \mathrm{~h}$ of mechanical alloying (MA) with BPR parameter at a level of 15:1. Obtained after (BM) and (MA) processing, typical powder morphology and size $(5-100 \mu \mathrm{m})$ was depictured on the example of 2 wt.\% of boron addition in Fig. 1. Precursors used for sinters preparation show typical cleavage fracture morphology with inhomogeneous size distribution and clustering tendencies for (MA) processed powders. After $48 \mathrm{~h}$ of (MA) crystallite size decreased to the nanoscale range $(10-50 \mathrm{~nm})$ in a process stadium that leads to clustering by milling to fragmentation, what was also confirmed in earlier research [10]. Micro and nano-precursors were cold compacted at a pressure of $1800 \mathrm{MPa}$. The specimens were sintered in a tube furnace at $1100^{\circ} \mathrm{C}$ for $1 \mathrm{~h}$, under $10^{-4}$ vacuum conditions, using a heating rate $20{ }^{\circ} \mathrm{C} / \mathrm{min}$ and slow furnace cooling. Sintered composites structures where marked and describe in Tab. 1 for clearance and next examined by X-ray diffraction (XRD), with $\mathrm{Cu} \mathrm{K \alpha 1}$ $(1.54 \AA)$ radiation with Panalytical Empyrean diffractometer. For microstructural examination, obtained compacts were ground and polished to 1-micron finish. Etching was performed in Kroll's reagent, and the microstructure was characterized using scanning electron microscopy. Hardness measurements were carried out on the samples in order to determine average

* POZNAN UNIVERSITY OF TECHNOLOGY, INSTITUTE OF MATERIALS SCIENCE AND ENGINEERING, M. SKLODOWSKA-CURIE 5 SQ., 60-965 POZNAN, POLAND

* Corresponding author: andrzej.miklaszewski@put.poznan.pl 
hardness by Innovatest Nexus Vickers tester with 10 indents an applied load of $300 \mathrm{~g}$ and loading time $10 \mathrm{~s}$. The density of the composites was measured by immersing the samples in water and using Archimedes' principle. Density values were next put together with the theoretical density (TD) calculated from the rule of mixtures, to determine the relative density (RD) as a proportion of above, measured in a percentage scale. Corrosion resistance parameters were determined in potentiodynamic tests performed in $0.1 \mathrm{M} \mathrm{NaCl}$ solution with a scanning rate of potential $0,5 \mathrm{mV} / \mathrm{s}$.
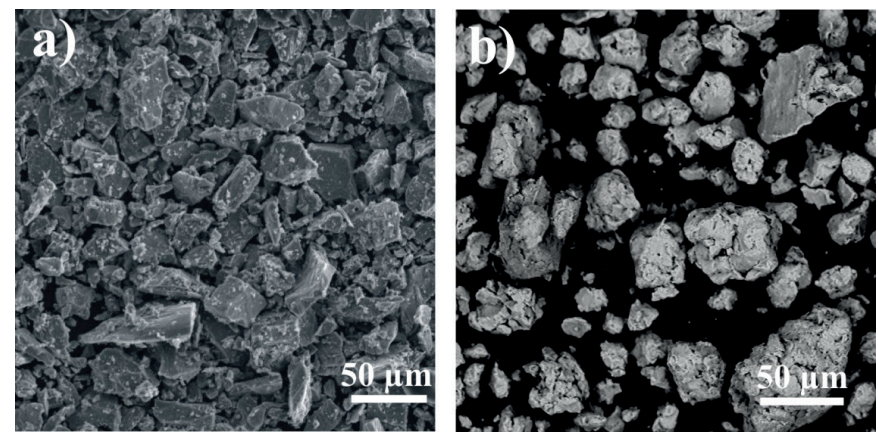

Fig 1. Precursor with 2 wt.\% of boron addition to titanium obtained with the different preparation method where a) represents (BM) and b) (MA) powders morphology

\section{Results and discussion}

XRD data of sintered compacts obtained from micro and nano precursor powders summarized in Fig. 2 confirmed the presence of $\operatorname{Ti}(\alpha)$ matrix and in situ $\mathrm{TiB}$ phase occurrence in all examined samples. Boron weight amount in starting precursor composition influence $\mathrm{TiB}$ phase volumetric ratio in final composite structure. Additionally, it was also noted that micro precursor powder with increasing amount of boron leads to $\mathrm{TiB}_{2}$ phase appearance during the sintering procedure. Undesirable but possible to obtained due to reaction kinetics (equation 1-3) between base elements, $\mathrm{TiB}_{2}$ phase occurrence could suggest from its unstable nature not complete reaction $[12,13]$.

$$
\mathrm{Ti}+\mathrm{B}=\mathrm{TiB}(1)
$$

$$
\begin{gathered}
\mathrm{Ti}+2 \mathrm{~B}=\mathrm{TiB}_{2}(2) \\
\mathrm{Ti}+\mathrm{TiB}_{2}=2 \mathrm{TiB}(3)
\end{gathered}
$$

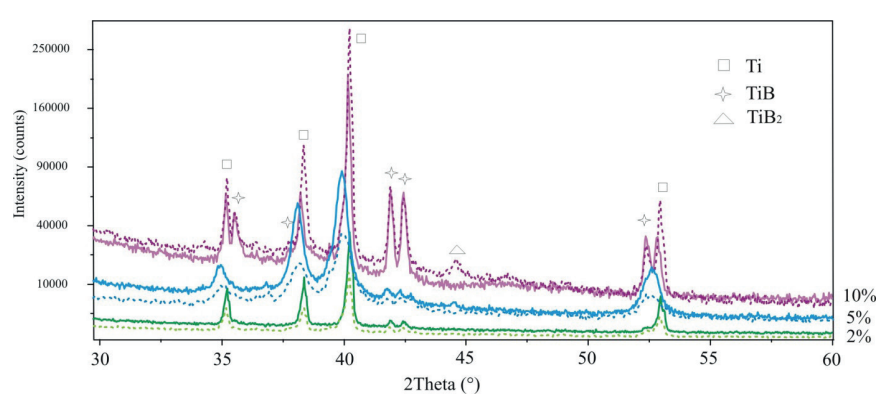

Fig 2. XRD spectra of sinters obtained from different starting precursor powder blends, doted lines presents micro(M) and continues ones nano(N) - based composite structure

Important to mention in this discussion is that the precursor powder character throughout its crystallite size dimension, substrate element distribution to increase structural defects concentration plays in above situation a crucial role, influencing the reaction kinetics for specified treatment conditions. Nano dimensional crystallites allow overreacting the substrates without local boron concentration. Presented data highlight also sharpness and intensity of differences between the reflexes obtained for nano and micro based sinters, especially visible for a higher starting boron concentration when comparing the inner relative intensity value of detected phases. Above discussion suggests also other difference due to applied precursor type like in obtained microstructure. Observations compiled in Fig. 3 reveal in obtained sinters, mainly characterized by the increased with boron amount, porosity level and TiB reinforcement volumetric ratio, microstructural dissimilarity. Different reaction kinetics suggested by XRD analysis could be confirmed by reinforcement phase size ratio observed for analyzed microstructure. For micro precursor powders obtained compacts characterized by a large (even $\sim 40 \mu \mathrm{m}$ ) polygonal grains of TiB phase with smaller one also occurring whisker morphology embedded in $\operatorname{Ti}(\alpha)$ matrix. Nano precursor based composites show highly dispersed TiB reinforcement phase with its growing size ratio due to boron amount in starting precursor composition.

TABLE 1

\begin{tabular}{|c|c|c|c|}
\hline Sample description & Composition & Precursor method preparation & Precursor treatment procedure \\
\hline $2 \mathrm{~N}$ & 2 wt. $\%$ of $B$ addition & MA & \multirow{6}{*}{$\begin{array}{c}\text { Step } 1 \text { - Compaction at pressure of } \\
1,8 \mathrm{GPa} \\
\text { Step } 2 \text { heat treatment } 1 \mathrm{~h} / 1100^{\circ} \mathrm{C} \\
\text { VAC }\end{array}$} \\
\hline $2 \mathrm{M}$ & 2 wt. $\%$ of $\mathrm{B}$ addition & $\mathrm{BM}$ & \\
\hline $5 \mathrm{~N}$ & $5 \mathrm{wt} . \%$ of $\mathrm{B}$ addition & MA & \\
\hline $5 \mathrm{M}$ & 5 wt. $\%$ of $\mathrm{B}$ addition & $\mathrm{BM}$ & \\
\hline $10 \mathrm{~N}$ & $10 \mathrm{wt} . \%$ of $\mathrm{B}$ addition & MA & \\
\hline $10 \mathrm{M}$ & 10 wt. $\%$ of $B$ addition & $\mathrm{BM}$ & \\
\hline
\end{tabular}

Sample markings description table that includes precursor composition its method of preparation and final treatment procedure. Description in the text 
TABLE 2 Summarized properties of obtained sinters after precursor treatment procedure compared with the reference microcrystalline titanium Ti-G2 sample. Description in the text

\begin{tabular}{|c|c|c|c|c|c|}
\hline \hline Sample & TD $\left[\mathrm{g} / \mathrm{cm}_{3}\right]$ & RD $[\%]$ & HV0,3 & I corr $\left[\mu \mathrm{A} / \mathrm{cm}_{2}\right]$ & $\mathrm{V}$ corr $[\mathrm{V}]$ \\
\hline $\mathrm{Ti}$ & 4.507 & $99.25 \pm 1.4$ & $180 \pm 16$ & 0.532 & -0.338 \\
\hline $2 \mathrm{~N}$ & 4.466 & $93.16 \pm 2.3$ & $650 \pm 22$ & 0.439 & -0.513 \\
\hline $2 \mathrm{M}$ & 4.466 & $95.88 \pm 3.3$ & $380 \pm 12$ & 0.151 & -0.537 \\
\hline $5 \mathrm{~N}$ & 4.405 & $87.51 \pm 2.3$ & $790 \pm 42$ & 0.581 & -0.461 \\
\hline $5 \mathrm{M}$ & 4.405 & $86.43 \pm 3.6$ & $480 \pm 23$ & 0.320 & -0.418 \\
\hline $10 \mathrm{~N}$ & 4.302 & $83.10 \pm 2.8$ & $950 \pm 65$ & 0.065 & -0.167 \\
\hline $10 \mathrm{M}$ & 4.302 & $90.18 \pm 3.8$ & $620 \pm 26$ & 8.582 & -0.648 \\
\hline
\end{tabular}
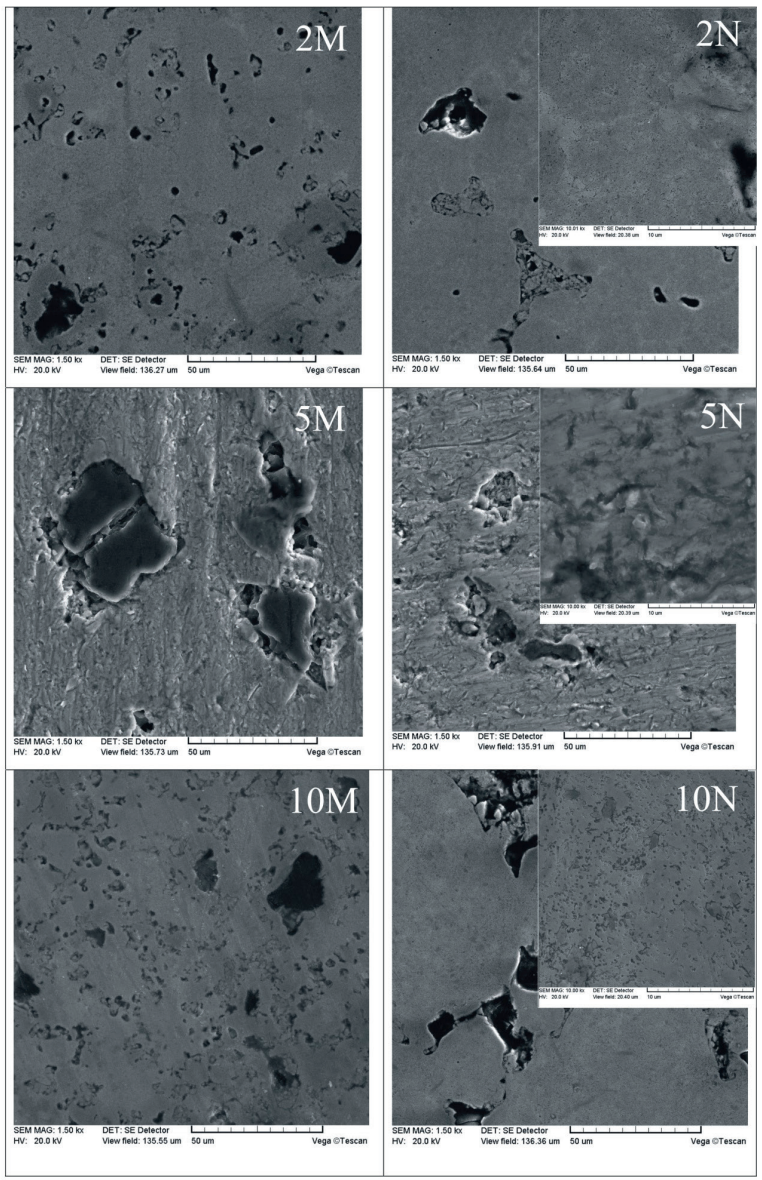

Fig 3. The microstructure of sintered compacts obtained from micro(M) - left hand and nano(N) precursor powders

Precursor type and the boron weight amount in starting composition influence significantly influenced composite densities summarized in Tab. 2. Increasing simultaneously with boron amount reinforcement phase share, reveals also porosity occurrence. For micro precursor type materials, the voids appearance in sinters (small and scattered) relates to the matrix/reinforcement interface region, unlike to nano precursor that microstructure observation mostly exhibits primary powder aggregates boundary location (large and sporadic). Calculated relative densities (RD) show in the same the dependence with the final reinforcement phase amount that increase diminish determined value. In reverse to above relation remain hardness increase, which average value reliance is founded on the reinforcement phase amount and distribution. Quoted factors dominate more visible estimated value when comparing the precursor type materials. Smaller and occurring more often reinforcement phase, strength the structure more strongly restricting grain boundary movement. In accordance with summarized in Tab. 2 hardness values, $2 \mathrm{~N}$ and $10 \mathrm{M}$ samples example, reveal that a smaller amount of boron addition into the starting precursor powders, allows to obtain similar strengthening effect. Obtained for the sinters significant hardness differences results reliant from the precursor type, could be in the same explained by a uniformly and highly dispersed boron particle distribution assure at (MA) processing stage. Nanocrystallite size dimension with obtained highly structural defect concentration accumulate through material plastic deformation, leads to an enormous number of reinforcement nucleation centres and total grain boundary mechanism strengthening. Discussed relation remains also connected with the reaction kinetics by available energy from total grain boundary length.

Present in Fig. 4 and summarized in Tab. 2 polarization curves results suggest for the obtained sinters corrosion potential relation to TiB phase amount. Analysed for sinters samples potentiodynamic test results confirmed corrosion potential shift to more noble values with increased shear of TiB reinforcement phase presence. Discussed relation corresponds also to the corrosion resistance increase by measured lower corrosion current densities. With refer to $\mathrm{XRD}$ and microstructural analysis, above relation could be however disturbed by another phase appearance, in our case $\mathrm{TiB}_{2}$. The third phase with the different potential influence its aggregate value and in the same increases the speed of surface reaction with electrolyte, leading directly to corrosion current densities increase and in the same manifests in lower corrosion resistance properties. Summarized in Tab. 2 and compared with a microstructural titanium sample data show that corrosion properties of analyzed in $0.1 \mathrm{M} \mathrm{NaCl}$ solution composites, could be competitive. Reassuming and concerning to above, final microstructure resulting from a composition, starting substrates preparation and treatment conditions, however, needs to be controlled. A global view on discussed results shows the possibilities to overcome the limitations of the titanium as material, without deterioration of its desirable properties. 


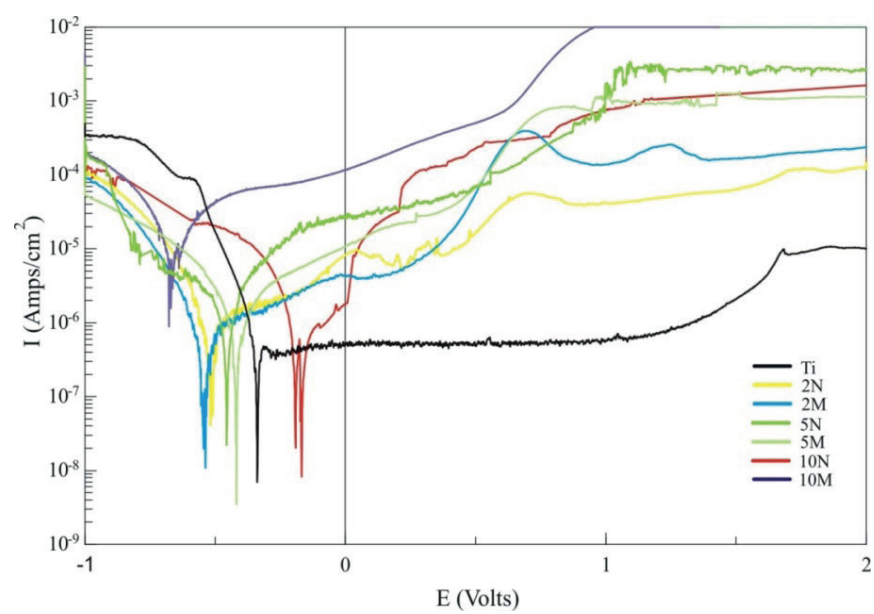

Fig. 4. Polarisation curves plotted for sinters obtained from different starting precursor in $0.1 \mathrm{M} \mathrm{NaCl}$ solution

\section{Conclusions}

In this work titanium powders mixed with different content of boron weight amount was used for a synthesis of in situ TiB reinforced titanium matrix composite. The studies lead to the following conclusions:

- Traditional powder metallurgical approach of cold compaction and sintering of prepared micro and nano precursor allow to obtaine nearly fully dense titanium matrix composite sinters with in situ $\mathrm{TiB}$ and $\mathrm{TiB}_{2}$ reinforcement phases.

- Precursor powder character throughout it crystallite size dimension, substrate element distribution to increase structural defects concentration influence the reaction kinetics and obtained final microstructure of composites for specified treatment conditions.

- Starting precursor size and composition influence obtained composite density measurements.

- $\quad$ Starting precursor size and composition influence TiB reinforcement phase amount its morphology and obtained in the same measured composites properties alike microhardness and corrosion resistance.

\section{Acknowledgements}

The research financed from the funds of the National Science Centre decision No. DEC-2014/13/N/ST8/00601.

\section{REFERENCES}

[1] R.R. Boyer, G. Welsch, E.W. Collings, Materials Properties Handbook: Titanium Alloys, ASM International, Materials Park, OH, (1994).

[2] K. Morsi, V. Patel, Processing and properties of titaniumtitanium boride (TiBw) matrix composites: a review, J. Mater. Sci. 42 2037-2047 (2007).

[3] K.S. Ravi Chandran, K.B. Panda, S. Sahay, TiBw-reinforced Ti composites: processing, properties, application prospects, and research needs, JOM J. Miner. Met. Mater. Soc. 56 42-48 (2004).

[4] S. Gorsse, D.B. Miracle, Mechanical properties of Ti-6Al$4 \mathrm{~V} / \mathrm{TiB}$ composites with randomly oriented and aligned $\mathrm{TiB}$ reinforcements, Acta Mater. 51 2427-2442 (2003).

[5] M. Zadra, L. Girardini, High-performance, low-cost titanium metal matrix composites, Materials Science and Engineering, A 608, 1, 155-163 July 2014.

[6] Z. Yan , F. Chen, Y. Cai, Y. Zheng, Microstructure and mechanical properties of in-situ synthesized TiB whiskers reinforced titanium matrix composites by high-velocity compaction, Powder Technology 267, 309-314 (2014).

[7] M. Selvakumar, P. Chandrasekar, M. Mohanraj, B. Ravisankar, J.N. Balaraju, Role of powder metallurgical processing and TiB reinforcement on mechanical response of Ti-TiB composites, Materials Letters 144, 58-61 (2015).

[8] L. Ropars, M. Dehmas, S. Gourdet, J. Delfosse ,D. Tricker, E. Aeby-Gautier, Structure evolutions in a Ti-6Al-4V matrix composite reinforced with $\mathrm{TiB}$, characterised using high energy X-ray diffraction, Journal of Alloys and Compounds 624, 179-188 (2015).

[9] K. Morsi, V.V. Patel, S. Naraghi, J.E. Garay, Processing of titanium-titanium boride dual matrix composites, Journal of Materials Processing Technology 196, 236-242 (2008).

[10] [10] A. Miklaszewski, Effect of starting material character and its sintering temperature on microstructure and mechanical properties of super hard $\mathrm{Ti} / \mathrm{TiB}$ metal matrix composites, Int. Journal of Refractory Metals and Hard Materials 53, 56-60 (2015).

[11] T. Saito, The Automotive Application of Discontinuously Reinforced TiB-Ti Composites, JOM May 2004.

[12] Y. Liang, Y. Che, Notebook of Thermodynamic Data of Inorganic, East-north University Press, Shen yang, (1996).

[13] Z. Xinghong, X. Qiang, H. Jiecai, V. Kvanin, Self-propagating high temperature combustion synthesis of TiB/Ti composites, Mater. Sci. Eng., A 348, 41-46 (2003). 